\title{
Registro de ocorrência de vetores da esquistossomose mansônica em açude do Sertão de Pernambuco
}

\author{
Occurrence of snail vectors of schistosomiasis in a dam of the \\ semi-arid region of Pernambuco State, Brazil
}

Pierre Gazin', Constança Simões Barbosa ${ }^{2}$, Marc Bouvy³ e Pierre Audry4

\begin{abstract}
Resumo O Sertão de Pernambuco não é área endêmica nem focal para esquistossomose mansônica. O presente trabalho registra a ocorrência de Biomphalaria straminea em açude da região, constatando que suas águas têm características físico-químicas favoráveis à proliferação destes moluscos. Chama a atenção para a possibilidade da introdução da doença no semiárido, diante da crescente multiplicação de barragens.
\end{abstract}

Palavras-chaves: Biomphalaria straminea. Esquistossomose. Características físico-químicas. Açudes.

Abstract The semi-arid region of Pernambuco state is not an endemic or focal area for schistosomiasis. The present work registers the occurrence of Biomphalaria straminea in a local dam with favorable chemical-physical characteristics to the proliferation of these mollusks. This observation gets the attention for the possibility of the introduction of the disease in this semi-arid region due to the growing multiplication of these dams.

Key-words: Biomphalaria straminea. Schistosomiasis. Physical-chemical caracteristics. Dams.

Em Pernambuco, a esquistossomose mansônica vem sendo historicamente considerada como endemia rural, com elevadas prevalências em algumas localidades da zona da mata ${ }^{2}$. Atualmente, a doença vem ocorrendo também em novos biótipos criados pela urbanização desordenada da zona costeira ${ }^{1}$. Existem raros registros de casos autóctones de esquistossomose em moradores da região semi-árida do Sertão, sendo todos eles decorrentes de situações especiais de ocupação da terra ${ }^{3}$. Os moluscos hospedeiros intermediários são da espécie Biomphalaria glabrata, com ocorrência em focos isolados no litoral do estado, e $B$. straminea que tem ampla distribuição na zona de mata podendo ser encontrada até os limites da região agreste.

O Alto do Pajeú, sertão de Pernambuco, tem uma média pluviométrica anual de $700 \mathrm{~mm}$ com $3.100 \mathrm{~mm}$ de demanda evapotranspiratória. Numerosos açudes foram construídos para compensar a ausência de água de superfície e suportar os longos períodos de estiagem. Estes recursos hídricos tornam possíveis as práticas agrícolas e de pecuária, características da região. O ano de 1998 apresentou um grande déficit de chuvas com apenas $325 \mathrm{~mm}$ de dezembro de 1997 a dezembro de 1998, razão pela qual os açudes foram secando gradativamente.

\footnotetext{
1. Departamento de Medicina Tropical da Universidade Federal de Pernambuco;2. Departamento de Parasitologia do Centro de Pesquisas Aggeu Magalhães/FIOCRUZ; 3. Departamento de Pesca da Universidade Federal Rural de Pernambuco; 4. Departamento de Energia Nuclear da Universidade Federal de Pernambruco, Recife, PE.

Endereço para correspondência: Dra. Constança Simões Barbosa. Centro de Pesquisas Aggeu Magalhães/FIOCRUZ. Campus da UFPE, 50670-420, Recife, PE, Brasil.

Telefax: 5581 271-4000/4553-1911.

e-mail: cbarbosa@cpqam.fiocruz.br

Recebido para publicação em 10/6/99.
} 
Diante destas circunstâncias, o pequeno açude de Flocos, no município de Tuparetama, com uma superfície aproximada de 4 ha e $3 \mathrm{~m}$ de profundidade máxima não chegava a medir mais que $2.500 \mathrm{~m}^{2}$ e $0,60 \mathrm{~m}$ no mês de novembro de 1998. Nesta ocasião, foram encontrados numerosos moluscos neste açude, numa densidade da ordem de $30 / \mathrm{m}^{2}$, a maioria fixada a plantas macrófitas do gênero Elodea. Esta angiosperma é encontrada em ambientes lacustres pouco túrbidos e a pouca profundidade. $O$ açude secou completamente no mês de dezembro, voltando a receber um pouco de águas pluviais em março de 1999. Por esta época, os moluscos foram novamente observados, desta vez mais ao fundo do açude e menos fixados nas Elodea que estavam no início de seu crescimento. O exame da concha e do aparelho genital destes moluscos permitiu sua identificação como pertencentes à espécie $B$. straminea.

Este açude é peculiar nesta região, sendo o mais antigo. Em cerca de um século de existência raramente chegou a secar (somente três vezes nos últimos vinte anos). Seu abastecimento se dá a partir de uma bacia hidrográfica que é capaz de fornecer grande quantidade de água de acordo com o volume do açude o que permite seu sangramento freqüente. A salinidade das águas que chegam é muito fraca (condutividade elétrica perto de $100 \mu \mathrm{S} / \mathrm{cm}$ ). Os sangramentos impedem o risco de salinização que é freqüente nesta região. Mesmo em 1998, apesar da falta de chuvas e sangramentos, Flocos apresentou uma condutividade de apenas $211 \mu \mathrm{S} / \mathrm{cm}$ (em agosto) e 350 em novembro. Neste açude, a concentração de clorofila (índex de biomassa de alga) é fraca, perto de $4 \mu \mathrm{g} / \mathrm{l}$, um valor bem menor do que o observado em reservatórios da região (média de $63 \mu \mathrm{g} / \mathrm{l})$. O pH é perto da neutralidade (valor de 7,2 na superfície) enquanto o pH médio na região é de 8,15. Assim, as características físicoquímicas da água de Flocos parecem sensivelmente diferentes daquelas de outros reservatórios. Estas condições ambientais (presença de macrófitas, a fraca condutividade da água e a neutralidade do $\mathrm{pH}$ ) parecem satisfazer as exigências ecológicas de $B$. straminea.

O açude de Flocos é um reservatório privado, cercado de arame farpado, onde as pessoas não costumam se banhar. Os únicos que raramente entram na água são dois trabalhadores locais, para a manutenção de uma bomba de sucção ou para a repicagem do capim. Não foram observados sinais de defecação humana nos arredores do açude. Duas famílias habitam nas proximidades, em casas de alvenaria que possuem sanitários com fossas fechadas. No exame parasitológico de fezes destas famílias não foram detectados ovos de Schistosoma mansoni ou de outros helmintos intestinais.

A simples observação de moluscos hospedeiros de S. mansoni no Sertão de Pernambuco não se constitui um fato inquietante por si só. Contudo, os raros registros de ocorrência destes moluscos nas partes áridas do Nordeste significam um alerta de que esta situação não é imutável. Os moluscos podem proliferar em biótipos favoráveis criados pelos homens e, com a crescente multiplicação destes açudes, existe o risco da introdução da esquistossomose no Sertão, que merece sempre ser levado em consideração. Não se justifica, entretanto, uma interrupção das atividades de implementação de obras para manter as águas de superfície, essenciais para o desenvolvimento da região.

\section{REFERÊNCIAS BIBLIOGRÁFICAS}

1. Barbosa CS, Gonçalves F, Albuquerque Y, Barbosa FS. Urban schistosomiasis in Itamaracá Island, Pernambuco, Brazil: epidemiological factors involved in the recent endemic process. Memórias do Instituto Oswaldo Cruz 93:265-266, 1998.

2. Barbosa CS, Silva CB. Epidemiologia da esquistossomose mansônica no Engenho Bela Rosa, município de São Lourenço da Mata, Pernambuco, Brasil. Cadernos de Saúde Pública 8:83-87, 1992.
3. Coutinho A, Silva M, Gonçalves F. Estudo epidemiológico da esquistossomose mansônica em áreas de irrigação do nordeste brasileiro. Cadernos de Saúde Pública 8:302310, 1992.

4. Pellon AB, Teixeira I. Distribuição geográfica da esquistossomose mansônica no Brasil. Ministério de Educação e Saúde. Trabalho da Divisão de Organização Sanitária, Rio de Janeiro, 1950. 